\title{
Separation Options for Phosphorylated Osteopontin from Transgenic Microalgae Chlamydomonas reinhardtii
}

\author{
Ayswarya Ravi ${ }^{1}$, Shengchun Guo ${ }^{1}$, Beth Rasala ${ }^{2}$, Miller Tran ${ }^{2}$, Stephen Mayfield ${ }^{3}$ and \\ Zivko L. Nikolov ${ }^{1, *}$ \\ 1 Department of Biological and Agricultural Engineering, Texas A\&M University, College Station, TX 77843, \\ USA; raviays.10h@tamu.edu (A.R.); guoshengchun121@tamu.edu (S.G.) \\ 2 Triton Algae Innovations, San Diego, CA 92121, USA; beth@tritonai.com (B.R.); miller@tritonai.com (M.T.) \\ 3 California Center of Algae Biotechnology, University of California San Diego, San Diego, CA 92093, USA; \\ smayfield@ucsd.edu \\ * Correspondence: znikolov@tamu.edu; Tel.: +1-979-458-0763
}

Received: 21 November 2017; Accepted: 13 February 2018; Published: 16 February 2018

\begin{abstract}
Correct folding and post-translational modifications are vital for therapeutic proteins to elicit their biological functions. Osteopontin (OPN), a bone regenerative protein present in a range of mammalian cells, is an acidic phosphoprotein with multiple potential phosphorylation sites. In this study, the ability of unicellular microalgae, Chlamydomonas reinhardtii, to produce phosphorylated recombinant OPN in its chloroplast is investigated. This study further explores the impact of phosphorylation and expression from a "plant-like" algae on separation of OPN. Chromatography resins ceramic hydroxyapatite (CHT) and Gallium-immobilized metal affinity chromatography (Ga-IMAC) were assessed for their binding specificity to phosphoproteins. Non-phosphorylated recombinant OPN expressed in E. coli was used to compare the specificity of interaction of the resins to phosphorylated OPN. We observed that CHT binds OPN by multimodal interactions and was better able to distinguish phosphorylated proteins in the presence of $250 \mathrm{mM} \mathrm{NaCl}$. Ga-IMAC interaction with OPN was not selective to phosphorylation, irrespective of salt, as the resin bound OPN from both algal and bacterial sources. Anion exchange chromatography proved an efficient capture method to partially separate major phosphorylated host cell protein impurities such as Rubisco from OPN.
\end{abstract}

Keywords: recombinant osteopontin; C. reinhardtii; protein; phosphorylation; ceramic hydroxyapatite; gallium; Ga-IMAC; purification; OPN

\section{Introduction}

The work horse of complex protein production for nearly $56 \%$ of recombinant proteins is the mammalian Chinese hamster ovary (CHO) cell line [1]. The ability of mammalian cells to properly fold and perform post-translational modifications (PTMs) of proteins, out-weighs the high cultivation costs and potential viral contamination issues. Escherichia coli is also extensively employed to produce recombinant proteins and does so at a fraction of the $\mathrm{CHO}$ cost but the resultant proteins often lack proper folding, PTMs and are prone to endotoxin contamination [2]. To overcome the disadvantages of mammalian and bacterial expression, the unicellular microalga Chlamydomonas reinhardtii has been explored as an alternative protein production platform. Specifically, the chloroplast of $C$. reinhardtii has been utilized for the production of difficult-to-express proteins that require specific folding and PTMs to exhibit biological function [3-7].

One such mammalian protein is osteopontin (OPN), also called bone sialoprotein-1 (BSP1), which is present in milk, bodily fluids and is responsible for bone development and regeneration. Other 
crucial functions of OPN include prevention of renal calcifications, protecting cells from apoptosis [8] and cytokine activity that differentially regulates inflammatory and immune response to allergic reactions [9]. The native mammalian form of OPN is an acidic, glycosylated sialoprotein, rich in aspartic acid, glutamic acid and serine residues [10]. Nascent bovine OPN is a $\sim 34 \mathrm{kDa}(\sim 300$ amino acid) protein, with an isoelectric point (pI) of 4.3, an arginine-glycine-aspartic acid (RGD) motif, a thrombin cleavage site, a polyaspartate domain and multiple calcium binding sites. In addition, twenty-eight potential phosphorylation sites and 3 glycosylation sites have been identified in the structure of OPN [11,12]. OPN's phosphorylation apparently provides a stabilizing effect on the bond between calcium and hydroxyapatite in bones [13], regulates the interaction of OPN with integrins during signaling in CD44 mediated immune responses [14] and is vital for inhibiting vascular calcification in smooth muscle cells [15]. Therefore, to take advantage of the diverse beneficial activities of OPN, a potential recombinant protein production system should also be able to deliver optimal in vivo OPN phosphorylation.

Despite the immense potential of OPN in the healthcare industry, reports dealing with recovery, purification and commercial applications have been relatively few. Attempts at purifying OPN from tissues and bones have been confined to affinity-tag chromatography [16-19], which only allows the production of limited amounts for OPN characterization and functionality assays.

Most of the methods employed to purify larger quantities of OPN, relied on generic protein properties such as hydrophobicity and ionic charge. Early reports with human milk employ weak anion exchange chromatography followed by several low capacity processing steps that resulted in low OPN yields due to losses from the multiple purification steps $[20,21]$. Currently, the primary source of OPN is bovine milk whey, which is processed by two consecutive anion exchange chromatography steps or anion exchange chromatography followed by two consecutive hydrophobic interaction chromatography steps [22,23]. Understandably, anion exchange adsorption is the default choice for capture and concentration of acidic OPN. It appears that consideration of other resin chemistries to increase process selectivity and yield warrants further investigation. The question to ask is whether the polyaspartate cluster (88-93 AA) and multiple phosphorylation sites in OPN can be exploited to achieve a more specific interaction with chromatographic adsorbents carrying transition metals and $\mathrm{Ca}^{2+}$ ions.

Therefore, the specific objectives of this study were (1) to assess the feasibility of chloroplast of the microalgae C. reinhardtii to produce phosphorylated OPN and (2) to evaluate OPN recovery and adsorption chromatography options that could take advantage of phosphorylation and/or polyaspartate sequences in the OPN structure. To evaluate the performance of algal-produced OPN, E. coli transformed with same OPN gene construct was used as benchmark.

\section{Results and Discussion}

\subsection{Expression and Characterization of Recombinant Osteopontin in C. reinhardtii and E. coli}

The transgenic cells of $C$. reinhardtii and E. coli expressing OPN were created by Mayfield's group at California Center of Algae Biotechnology, University of California San Diego (UCSD) [24] and biomass was grown at Texas A\&M University. Quantification of OPN concentration in C. reinhardtii lysates was difficult because of the low expression levels and interference of lysate components with enzyme-linked immunosorbent assay (ELISA). In the absence of a reliable quantification method, we relied on band density analysis of western blots with ImageJ software (v.1.49, U. S. National Institutes of Health, Bethesda, MD, USA), using FLAG-affinity purified OPN as a standard. C. reinhardtii OPN expression levels varied between biomass batches and was on average $4 \times$ lower than OPN in E. coli cells, as indicated by similar band densities of $4 \times$ and $16 \times$ diluted C. reinhardtii and E. coli cell lysates, respectively (Figure 1, lanes $2 \& 3$ ). In terms of initial OPN concentration expressed as a percent of total soluble protein (TSP), E. coli lysates contained $2.9 \%$ and algal lysates between $0.1 \%$ and $0.2 \%$ OPN. 


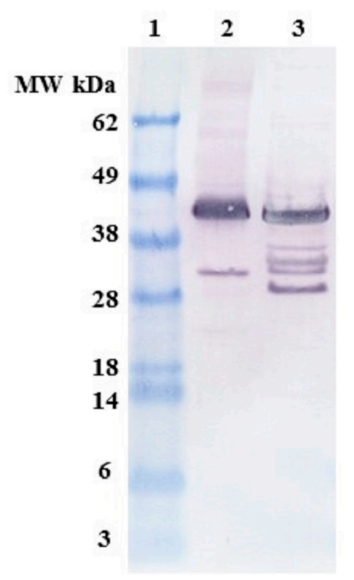

Figure 1. Anti-FLAG western blots showing N-terminal fragments of osteopontin (OPN). Lane 1. Molecular weight (MW) marker, lane 2. C. reinhardtii lysate diluted $4 \times$, lane 3. E. coli lysate diluted $16 \times$.

Full-length recombinant OPN migrated to an apparent molecular weight of $45 \mathrm{kDa}$. This observation was consistent with the varied molecular weight (75-44 kDa) of OPN reported in literature and was attributed to the highly acidic nature of the protein [25,26]. OPN expressed in the chloroplast of $C$. reinhardtii (Lane 2) consists of a major $45 \mathrm{kDa}$ band and an $\mathrm{N}$-terminal $35 \mathrm{kDa}$ fragment. In addition to the $45 \mathrm{kDa}$ band, E. coli lysate (Lane 3) contains several $N$-terminal fragments with apparent molecular weights corresponding to 40, 38, 35, 30 and $28 \mathrm{kDa}$. There were considerably fewer $\mathrm{N}$-terminal fragments observed in algal lysates as compared to E. coli, suggesting that OPN is better protected from fragmentation in the chloroplast of $C$. reinhardtii than in the E. coli cytosol.

The FLAG-affinity-purified E. coli and C. reinhardtii OPNs were analyzed by 2D electrophoresis gel (Figure 2) to estimate $\mathrm{pI}$ of various OPN forms. The $45 \mathrm{kDa}$ OPN from C. reinhardtii resolved in a $\mathrm{pI}$ range from $\mathrm{pH} 3.5$ to $\mathrm{pH}$ 4.5. A similar streak of varying $\mathrm{pI}(\mathrm{pH} \sim 3.5$ to 4.0 ) was observed with the $35 \mathrm{kDa}$ fragment. The observed streaks suggest the presence of OPN isoforms that are likely due to heterogeneous post-translational phosphorylation and/or in vitro enzymatic de-phosphorylation. In contrast, E. coli $45 \mathrm{kDa}$ OPN resolved into a spot localized at $\mathrm{pH}$ 4.5. The E. coli OPN fragments were also localized at approximately the same $\mathrm{pH}$ 4.5. Single spots instead of streaks of E. coli OPN is consistent with the expected lack of protein phosphorylation in E. coli [27-29]. Additional spots probably belonging to $E$. coli host protein were also detected on $2 \mathrm{D}$ gels.

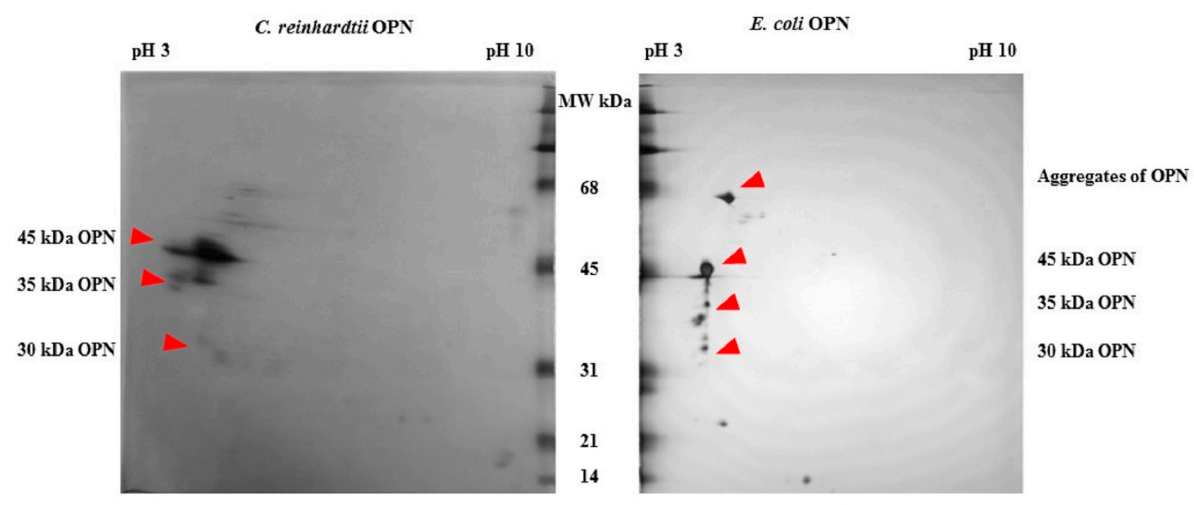

(a)

(b)

Figure 2. 2D gel electrophoresis of OPN from transgenic (a) C. reinhardtii and (b) E. coli lysates obtained by FLAG-affinity purification. 
The presence or absence of phosphorylation on the recombinant OPN was detected by phosphostaining an SDS-PAGE gel (Figure 3). The stained band in lane 4 indicates that the FLAG-affinity purified $45 \mathrm{kDa}$ OPN from C. reinhardtii is phosphorylated, while its counterpart from $E$. coli in lane 5 is not stained and, thus, not detectable. The phosphostained band in lane 1 belongs to $45 \mathrm{kDa}$ ovalbumin, which served as a phosphorylated protein marker. The absence of phosphostaining of the $35 \mathrm{kDa}$ band may indicate little or no phosphorylation.

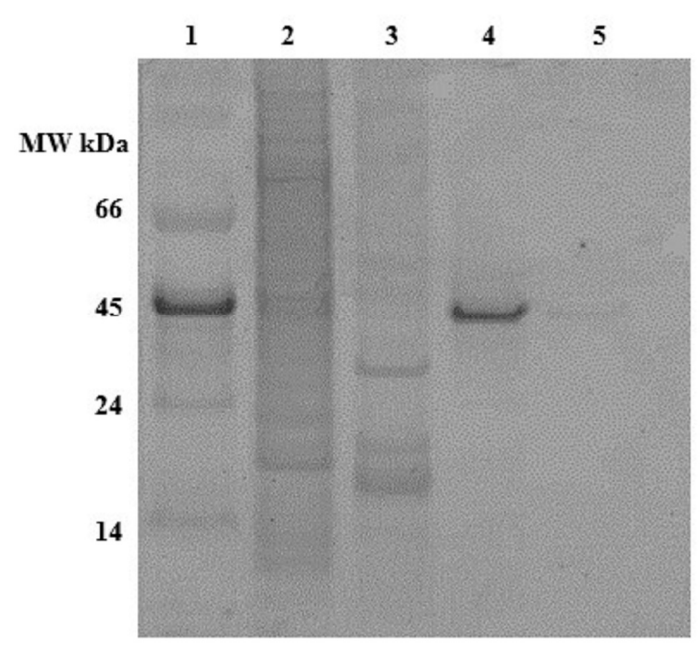

Figure 3. Pro-Q diamond phosphostained gel of OPN. Lane 1. MW marker, lane 2. C. reinhardtii lysate, lane 3. E. coli lysate, lane 4. Recombinant OPN purified from C. reinhardtii, lane 5. Recombinant OPN purified from E. coli. Each lane contains the same amount $(\sim 50 \mu \mathrm{g})$ of total soluble protein (TSP).

The detection of phosphorylated residues in algal $45 \mathrm{kDa}$ OPN provided motivation to look into the specificity of algal OPN interaction with ceramic hydroxyapatite (CHT) and immobilized transition metal $(\mathrm{Ga}, \mathrm{Fe}, \mathrm{Zn})$ resins.

\subsection{Ceramic Hydroxyapatite Chromatography}

The results from equilibrium adsorption of OPN to $\mathrm{CHT}$ resin from clarified C. reinhardtii and $E$. coli lysates are summarized in Figure 4.

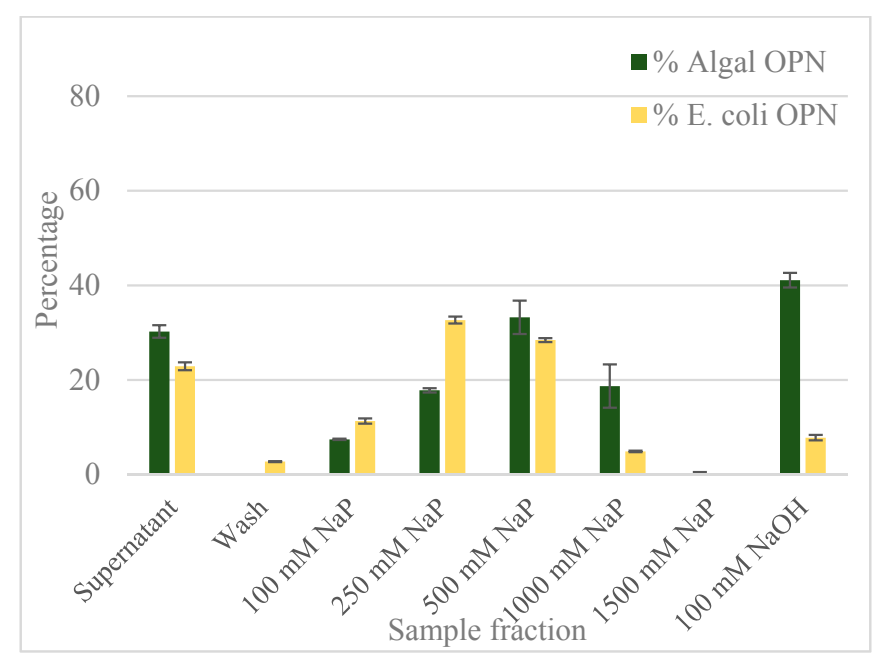

(a)

Figure 4. Cont. 


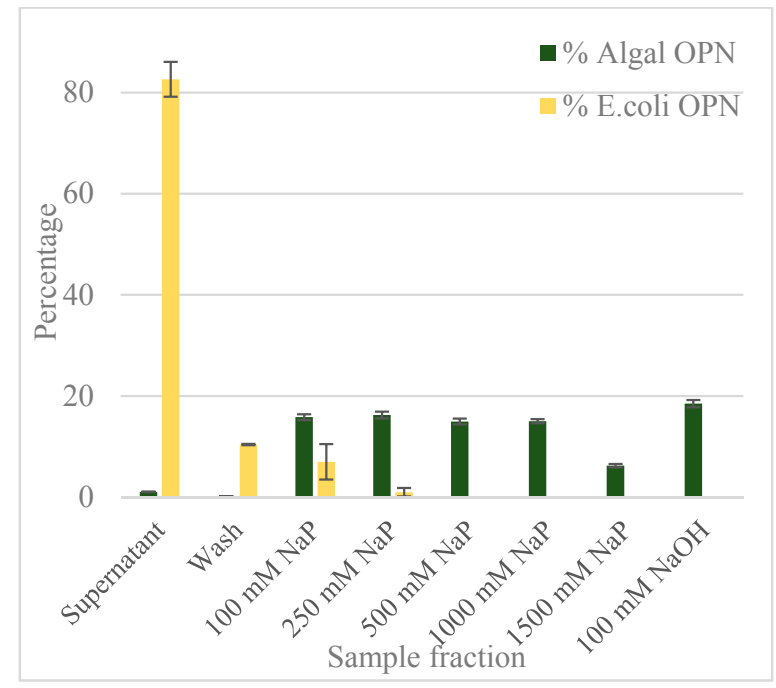

(b)

Figure 4. OPN distribution in fractions obtained with ceramic hydroxyapatite (CHT) resin (a) with no salt; (b) with $250 \mathrm{mM} \mathrm{NaCl}$. Step elutions were performed with sodium phosphate (NaP) buffer, $\mathrm{pH}$ 6.8. Data (\% OPN) were generated by ImageJ analysis of anti-FLAG western blots and normalized by the amount in the lysate. Error bars indicate standard deviation of triplicate ImageJ measurements.

The adsorbed E. coli and C. reinhardtii OPN, respectively, were eluted using increasing strength (100 to $1500 \mathrm{mM})$ of NaP buffer. The bar graph in Figure 4 a reveals that the majority $(>70 \%)$ of OPN from both lysates was adsorbed to the CHT resin in the absence of salt. The relatively low amount of C. reinhardtii OPN detected in the supernatant (30\%) and its absence in the wash fractions indicates strong interactions between OPN and CHT. The bound C. reinhardtii OPN began to elute with $100 \mathrm{mM} \mathrm{NaP}$ and continued eluting through $1000 \mathrm{mM}$ phosphate concentration. A significant fraction of adsorbed OPN eluted with the $250 \mathrm{mM}(18 \%)$ and $500 \mathrm{mM} \mathrm{NaP}(33 \%)$ steps, respectively. Since we could not close the mass balance on OPN in the eluted fractions, even after 5 column volumes (CV) elution with $1500 \mathrm{mM} \mathrm{NaP}$, we resorted to harsher desorption conditions using $100 \mathrm{mM} \mathrm{NaOH}$. The strongly adsorbed OPN, estimated at $41 \%$ of initial OPN by Image J analysis, was completely eluted with $100 \mathrm{mM} \mathrm{NaOH}$. Western blots (Figure 5b) show that the $35 \mathrm{kDa}$ fraction was eluted with $100 \mathrm{mM}$ $\mathrm{NaP}$ and that the $45 \mathrm{kDa}$ form interacted even more strongly, requiring higher phosphate concertation $>250 \mathrm{mM} \mathrm{NaP}$ and $100 \mathrm{mM} \mathrm{NaOH}$ for desorption.

As the bar graph in Figure $4 \mathrm{a}$ indicates, about $23 \%$ of E. coli OPN remained in the supernatant and $3 \%$ was found in the wash fractions. In contrast to C. reinhardtii, $72 \%$ of E. coli OPN eluted from hydroxyapatite resin in the 100-500 $\mathrm{mM}$ phosphate buffer range. As expected from the mass balance of OPN fractions eluted with the three $\mathrm{NaP}$ steps changes, the application of $100 \mathrm{mM} \mathrm{NaOH}$ did not yield a significant amount of OPN (only $8 \%$ of initial amount). The significant difference in the amount of $45 \mathrm{kDa}$ OPN eluted with $100 \mathrm{mM} \mathrm{NaP}$ (7\% algal OPN consisting of mainly $35 \mathrm{kDa}$ OPN vs. $11 \%$ of E. coli $45 \mathrm{kDa}$ OPN) and $100 \mathrm{mM} \mathrm{NaOH}(41 \%$ algal OPN vs. $8 \%$ E. coli OPN) steps indicate that E. coli and $C$. reinhardtii OPN interact differently with heterogeneous binding sites of $\mathrm{CHT}$ resin. 


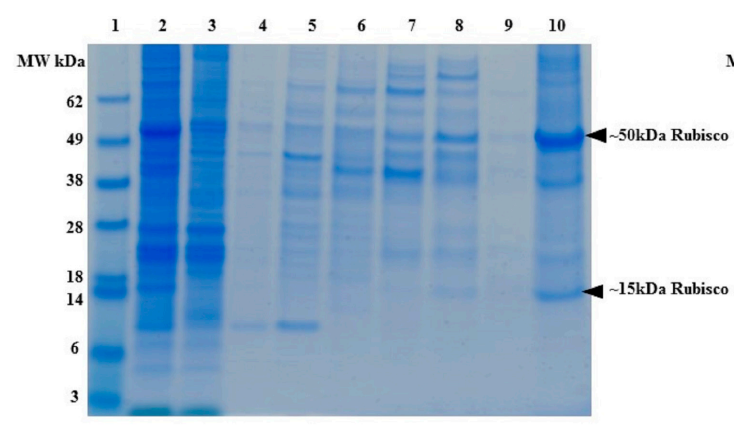

(a)

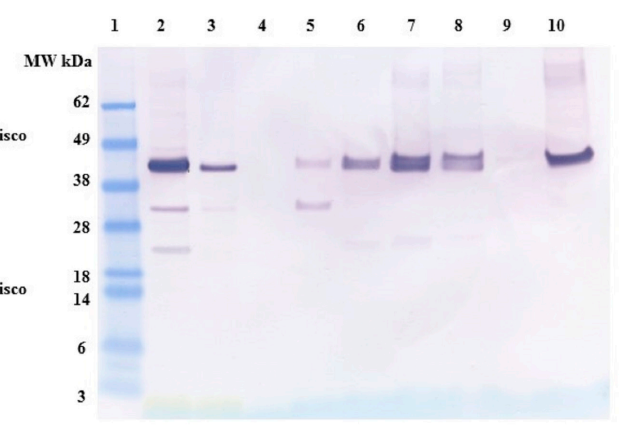

(b)

Figure 5. (a) SDS-PAGE and (b) Anti-FLAG western blot of $C$. reinhardtii lysate binding and elution profile from ceramic hydroxyapatite (CHT) resin without $250 \mathrm{mM} \mathrm{NaCl}$. All samples diluted to $<1 \mathrm{mg} / \mathrm{mL}$ TSP. Lane 1: MW marker, lane 2. Clarified lysate, lane 3. Supernatant, lane 4. Washes 3 column volumes (CV), lane 5. Elution with $100 \mathrm{mM} \mathrm{NaP}$, lane 6. Elution with $250 \mathrm{mM}$ NaP, lane 7. Elution with $500 \mathrm{mM} \mathrm{NaP}$, lane 8. Elution with $1000 \mathrm{mM} \mathrm{NaP}$, lane 9. Elution with $1500 \mathrm{mM}$ NaP, lane 10. Elution with $100 \mathrm{mM} \mathrm{NaOH}$. All elutions were performed with $5 \mathrm{CV}$ of the respective buffer.

To determine if the different interaction strengths of OPN with CHT were due to phosphorylation i.e., phosphorylated (C. reinhardtii) vs. non-phosphorylated (E. coli) OPN, the adsorption and elution experiments were repeated in the presence of $250 \mathrm{mM} \mathrm{NaCl}$ (Supplementary data Figure S1). The inclusion of $250 \mathrm{mM} \mathrm{NaCl}$ in the adsorption and elution buffers was intended to reduce ionic interactions of amino acid side chains of OPN with $\mathrm{Ca}^{2+}$ and $\mathrm{PO}_{4}{ }^{3-}$ sites on the CHT without disrupting the much stronger coordinate bonding between OPN's phosphoryl groups and $\mathrm{Ca}^{2+}$ on CHT surface. The results shown in Figure $4 \mathrm{~b}$ clearly demonstrate a difference in the adsorption of E. coli and C. reinhardtii OPN in the presence of salt. About $83 \%$ of E. coli OPN remains in the supernatant at the end of the adsorption period compared to the barely detectable amount $(\sim 1 \%)$ OPN in C. reinhardtii supernatants. An additional $10 \%$ of E. coli OPN was removed in the wash step while none of $C$. reinhardtii OPN was desorbed during the washing. Comparison of the data presented in Figure 4 demonstrates that the adsorption of E. coli OPN to CHT was significantly weakened by $250 \mathrm{mM} \mathrm{NaCl}$, whereas that of $C$. reinhardtii was not. The latter, somewhat atypical behavior of increased $\mathrm{C}$. reinhardtii OPN binding, can be explained by $\mathrm{NaCl}$ suppression of electrostatic repulsions between phosphoryl groups on OPN and $\mathrm{PO}_{4}{ }^{3-}$ sites on the CHT [30]. The suppression of electrostatic repulsions, results in enhanced interactions between algal OPN's phosphoryl groups with the $\mathrm{Ca}^{2+}$ on CHT surface.

Therefore, E. coli OPN probably binds to hydroxyapatite by electrostatic interactions as depicted in Figure 6 below. This observation is consistent with the reported multi-modal interaction of proteins with CHT via charge interactions between acidic and basic amino acid side chains with the $\mathrm{Ca}^{2+}$ and $\mathrm{PO}_{4}{ }^{3-}$ moieties on $\mathrm{CHT}$, respectively, which can be reversed by increasing the ionic strength of the buffer [31]. 


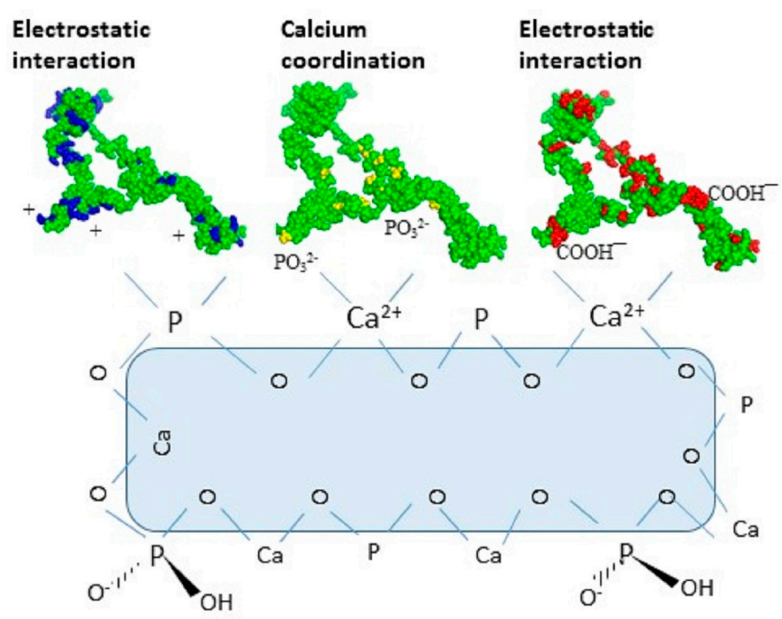

Figure 6. Proposed multimodal interaction mechanisms of OPN with ceramic hydroxyapatite (CHT) resin at $\mathrm{pH}$ 6.8. Basic (arginine, histidine and lysine) amino acids of OPN are shown in blue, phosphoryl groups in yellow and acidic (aspartic and glutamic acid) in red.

Based on these data, we believe that protein phosphorylation made a difference in the interaction of OPN with ceramic hydroxyapatite resin for the following reasons. First, compared to E. coli OPN, the addition of $\mathrm{NaCl}$ had a minimal or no measurable effect on $C$. reinhardtii OPN adsorption and elution from $\mathrm{CHT}$ (Figure 4). The presence of $\mathrm{NaCl}$ weakens $\mathrm{E}$. coli OPN interaction with $\mathrm{CHT}$ as evidenced by $83 \%$ of OPN remaining unbound in supernatant and the residual $17 \%$ being desorbed during wash and first step $100 \mathrm{mM} \mathrm{NaP}$ step (Figure $4 \mathrm{~b}$ ). Second, the elution of C. reinhardtii OPN, irrespective of ionic strength, required displacement by increasing phosphate concentration and complete desorption of phosphorylated OPN by the application of $100 \mathrm{mM} \mathrm{NaOH}$. This line of evidence suggests that $C$. reinhardtii OPN adsorption to $\mathrm{CHT}$ is mediated by the stronger $\mathrm{Ca}^{2+}-\mathrm{PO}_{3}{ }^{2-}$ coordinate binding rather than simple charge interactions. And, the unusually strong adsorption of the $45 \mathrm{kDa}$ C. reinhardtii OPN form, which required $100 \mathrm{mM} \mathrm{NaOH}$ for elution (Figure $5 \mathrm{~b}$ ), is probably the result of interaction of multiple, closely positioned phosphoryl $\left(\mathrm{PO}_{3}{ }^{2-}\right)$ groups on OPN molecule with calcium moieties $\left(\mathrm{Ca}^{2+}\right)$ of CHT resin.

To assess the specificity and purification capability of $\mathrm{CHT}$, we compared host protein binding and elution by SDS-PAGE (Figure 5a). Data in Figure 5a indicate that a significant number of algal proteins would co-elute with OPN. The major OPN "competitor" appears to be acidic, phosphorylated chloroplast protein, Rubisco [32], as large ( 50 kDa) and small subunit $(\sim 15 \mathrm{kDa})$ can be seen in $1000 \mathrm{mM} \mathrm{NaP}$ and $100 \mathrm{mM} \mathrm{NaOH}$ fractions (Figure 5a, lane 8 and 10 respectively). The identity of Rubisco was confirmed by western blots using anti-Rubisco large and small subunit antibodies (Supplementary data Figure S3). Thus, the presence of Rubisco in C. reinhardtii lysates would eventually reduce the resin breakthrough capacity and OPN purification fold, both of which are important factors in process scale-up. A possible solution to CHT application for OPN purification is to remove Rubisco and other interfering host protein impurities from the clarified lysates before OPN binding to CHT.

\subsection{Gallium-Immobilized Metal Affinity Chromatography (Ga-IMAC)}

Gallium, iron and zinc immobilized on Chelating Sepharose are known to bind phospho-peptides by coordinate bonds [33-35]. Gallium, having higher affinity than other metals for phosphorylated peptides [36], has been selected in this study to determine if differential interactions between $\mathrm{Ga}^{3+}$ and phosphorylated protein residues could be utilized for the separation of $C$. reinhardtii OPN from non-phosphorylated proteins. As before, E. coli OPN has been used to assess the specificity of OPN-Ga interactions due to phosphorylation. To eliminate any ionic interactions between the protein and Ga-IMAC resin, OPN adsorption and elution was tested in the presence of $150 \mathrm{mM}$ and $500 \mathrm{mM} \mathrm{NaCl}$. 
Results from Ga-IMAC batch adsorption chromatography are shown in Figure 7. Approximately $20 \%$ of $C$. reinhardtii OPN remained unbound in the supernatant compared to only $7 \%$ of $E$. coli OPN. An additional $8 \%$ of algal OPN was removed during the resin wash step. The majority of the unbound and wash fractions contained $35 \mathrm{kDa}$ form of algal OPN (Supplementary data Figure S2) which, as discussed above, did not bind strongly to $\mathrm{CHT}$ either. The adsorbed C. reinhardtii OPN started to elute with $100 \mathrm{mM} \mathrm{NaP}$ with $8 \%-12 \%$ of $45 \mathrm{kDa}$ OPN continuing to elute in each step elution up to $1000 \mathrm{mM}$ $\mathrm{NaP}$ concentration. The major fraction (21\%) of bound E. coli OPN was in the second step elution with $250 \mathrm{mM} \mathrm{NaP}$ (Figure 7). The remaining bound E. coli OPN was eluted with 500 and $1000 \mathrm{mM} \mathrm{NaP}$.

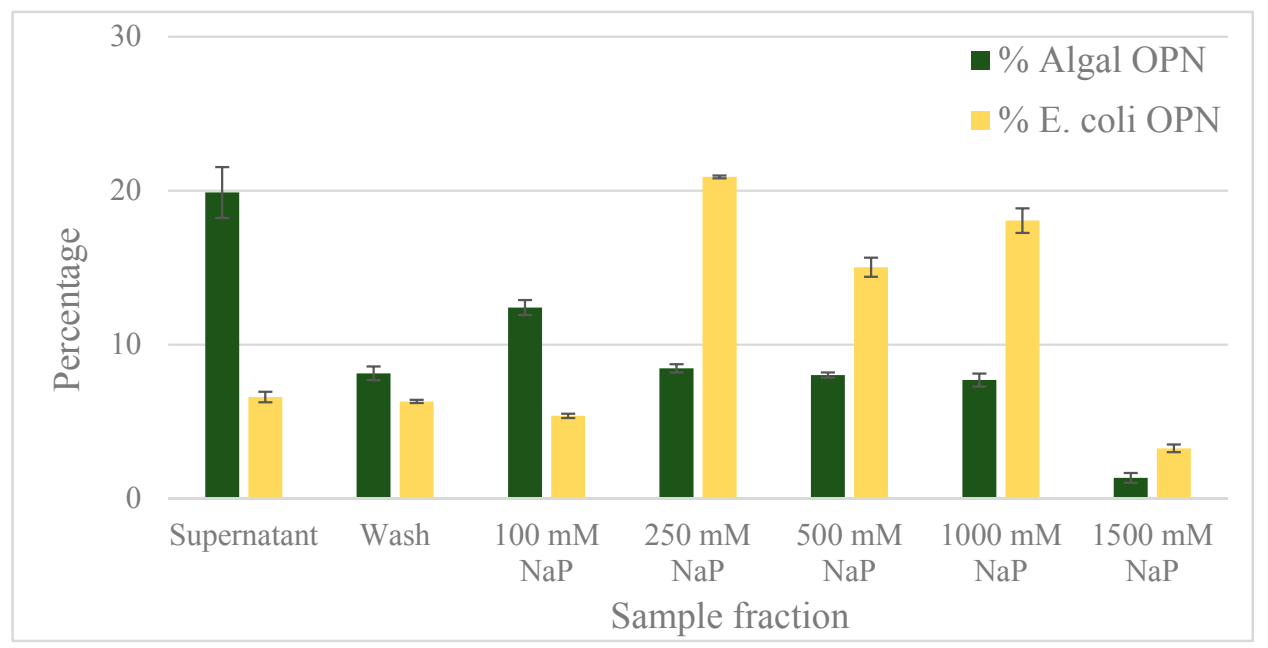

Figure 7. OPN distribution in fractions obtained with Ga-IMAC resin. Adsorption and elution was done in the presence of $500 \mathrm{mM} \mathrm{NaCl}$. Step elutions were performed with sodium phosphate (NaP) buffer, $\mathrm{pH}$ 5.5. Data (\% OPN) were generated by ImageJ analysis of anti-FLAG western blots and normalized by the amount in the lysate. Error bars indicate standard deviation of triplicate ImageJ measurements.

The binding mechanism of $C$. reinhardtii OPN to Ga-IMAC apparently does not involve phosphorylated residues because non-phosphorylated E. coli OPN binds and elutes similarly to phosphorylated C. reinhardtii OPN (Figure 7). In addition, the similar binding and elution profiles observed with Fe-IMAC resin suggests that OPN interacts with $\mathrm{Ga}^{3+}$ and $\mathrm{Fe}^{3+}$ via the multiple carboxylic acidic containing amino acids occurring in close proximity (carboxyl clusters) present in both E. coli and C. reinhardtii OPN. Unfortunately, we could not confirm this hypothesis because adsorption at or below $\mathrm{pH} 4.5$ (pKa of carboxyl groups) was not possible due to OPN precipitation at that $\mathrm{pH}$ range. Based on our data, it appears that protein interactions with transition metals $\left(\mathrm{Ga}^{3+}\right.$ or $\mathrm{Fe}^{3+}$ ) are not confined specifically to phosphorylated residues and, therefore, the application of Ga-IMAC resin would not be useful for the separation of $C$. reinhardtii OPN from other acidic algae proteins present in the lysates.

\subsection{Anion Exchange Chromatography}

Previous studies with E. coli OPN have used anion exchange chromatography as one of the purification steps $[37,38]$. The use of anion exchange adsorption is a natural choice for highly acidic proteins like OPN. We decided to compare the interaction of $C$. reinhardtii and E. coli OPN with a strong anion exchange resin (Capto Q, GE Healthcare Life Sciences, Marlborough, MA, USA). The analysis of binding and elution pools of OPN from both sources are summarized in the bar graph (Figure 8) and western blots (Figure 9). When bound at pH 7.0 and a low conductivity of $4 \mathrm{mS}$, OPN bound strongly and specifically to the resin. No C. reinhardtii OPN $(<1 \%)$ was detected by western blot in the supernatants and the washes (Figure 8). The majority of $C$. reinhardtii $35 \mathrm{kDa}$ OPN fragment, which constitutes $11 \%$ total OPN was eluted with $100 \mathrm{mM} \mathrm{NaCl}$ (Figure 9a lane 5) suggesting weaker 
interaction with the quaternary amine than the intact $45 \mathrm{kDa}$ form. The $45 \mathrm{kDa}$ OPN from C. reinhardtii eluted in $200-500 \mathrm{mM} \mathrm{NaCl}$ range reaching a peak concentration in the $300 \mathrm{mM} \mathrm{NaCl}$ elution fraction. A faint band ( 1.4\%) was also observed with $1000 \mathrm{mM} \mathrm{NaCl}$ elution (Figure 9a lane 9). E. coli OPN also bound on anion exchange column strongly, demonstrated by the lack of a band in the supernatant and washes (Figure $9 \mathrm{~b}$ lane 3 and 4). The elution of intact $45 \mathrm{kDa}$ E. coli OPN starts earlier than algal OPN, with $16 \%$ in $100 \mathrm{mM} \mathrm{NaCl}$ elution (Figure 9b, lane 5) and elution continues till $500 \mathrm{mM} \mathrm{NaCl}$ with the highest concentration $(37 \%)$ at $300 \mathrm{mM} \mathrm{NaCl}$ elution similar to C. reinhardtii OPN. The elution region for $E$. coli OPN is narrower under the same conditions with very little to no OPN over $500 \mathrm{mM} \mathrm{NaCl}$ elution. This observation corresponds to the $2 \mathrm{D}$ gel electrophoresis results, where $E$. coli OPN fragments were localized to spots, reflecting homogenous $\mathrm{pI}$ that should result in a uniform binding strength to the Capto $\mathrm{Q}$ resin. C. reinhardtii OPN had horizontal streaks on the $2 \mathrm{D}$ gel indicating a broader $\mathrm{pI}$ range of OPN due to heterogeneous phosphorylation. Hence, the elution profile of the adsorbed OPN would require a broader range of salt concentration to break the "heterogeneous" strength interactions with the resin. The ionic strength difference in the onset of $45 \mathrm{kDa}$ OPN elution, $200 \mathrm{mM}$ (C. reinhardtii) vs. $100 \mathrm{mM} \mathrm{NaCl}$ (E. coli OPN), probably reflects higher acidity of phosphorylated C. reinhardtii OPN.

SDS-PAGE (Figure 10) reveals that partial separation of OPN from C. reinhardtii host protein by anion exchange chromatography is possible. The majority ( $>99 \%)$ of recombinant algal OPN was adsorbed on the resin, about $49 \%$ of the host protein was present in the supernatant (lane 3) and wash fractions (lane 4) while the rest of the host protein was co-adsorbed with OPN. The majority of host protein was eluted in 100-300 $\mathrm{mM} \mathrm{NaCl}$ fractions (lanes 5-7), whereas, OPN eluted in 200-500 mM NaCl fractions (lanes 6-8). Thus, by pooling 200 to $500 \mathrm{mM} \mathrm{NaCl}$ elution fractions at least forty-fold increase of OPN purity (from $0.2 \%$ to $8 \%$ TSP) and $80 \%$ recovery can be achieved by anion exchange chromatography. The anion exchange data also demonstrate that a substantial fraction of phosphorylated host protein (Rubisco), which was identified above as the major interfering host protein for OPN purification with CHT, can be partially separated from OPN by excluding the $200 \mathrm{mM}$ $\mathrm{NaCl}$ elution and pooling only the 300 and $500 \mathrm{mM}$ fraction for further OPN isolation. In the latter case, OPN purity would increase to $20 \%$ at the expense of reduced recovery $(<60 \%)$ as calculated from Figure 10.

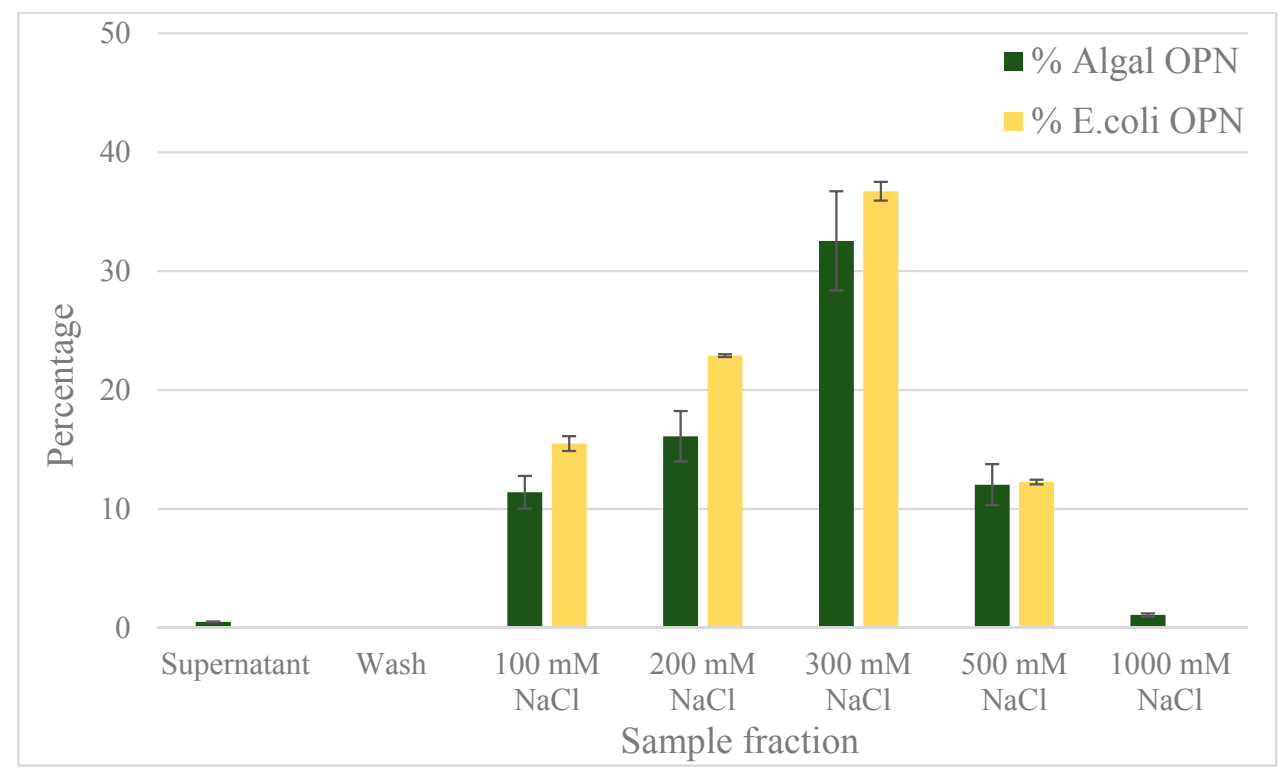

Figure 8. OPN distribution in fractions obtained with strong anion exchange resin (Capto Q). Step elutions were performed with sodium chloride in $50 \mathrm{mM}$ Tris $\mathrm{pH}$ 7.0. Data (\% OPN) were generated by ImageJ analysis of anti-FLAG western blots and normalized by the amount in the lysate. Error bars indicate standard deviation of triplicate ImageJ measurements. 


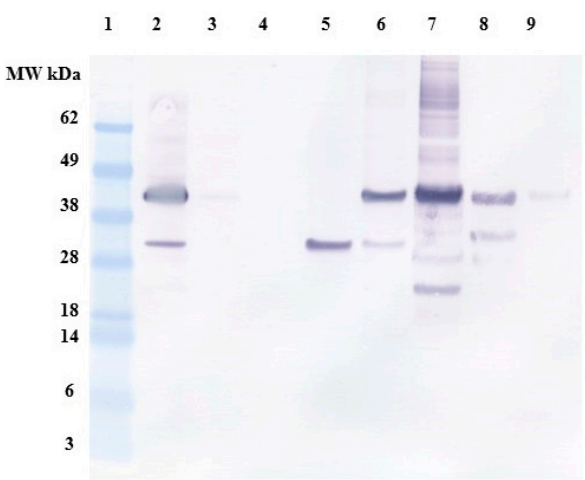

(a)

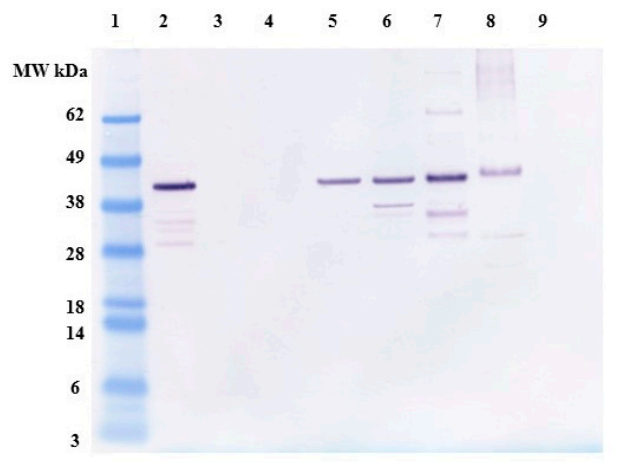

(b)

Figure 9. Anti-FLAG western blot of (a) C. reinhardtii (b) E. coli OPN binding and elution profile from Capto $\mathrm{Q}$ (strong anion exchange) resin. All samples diluted to $<1 \mathrm{mg} / \mathrm{mL}$ TSP. Lane 1 . MW marker, lane 2. Clarified lysate, lane 3. Supernatant, lane 4. Washes (3 CV), lane 5. Elution with $100 \mathrm{mM}$ $\mathrm{NaCl}$, lane 6. Elution with $200 \mathrm{mM} \mathrm{NaCl}$, lane 7. Elution with $300 \mathrm{mM} \mathrm{NaCl}$, lane 8. Elution with $500 \mathrm{mM} \mathrm{NaCl}$, lane 9. Elution with $1000 \mathrm{mM} \mathrm{NaCl}$. All elutions were performed with $5 \mathrm{CV}$ of the respective buffer.

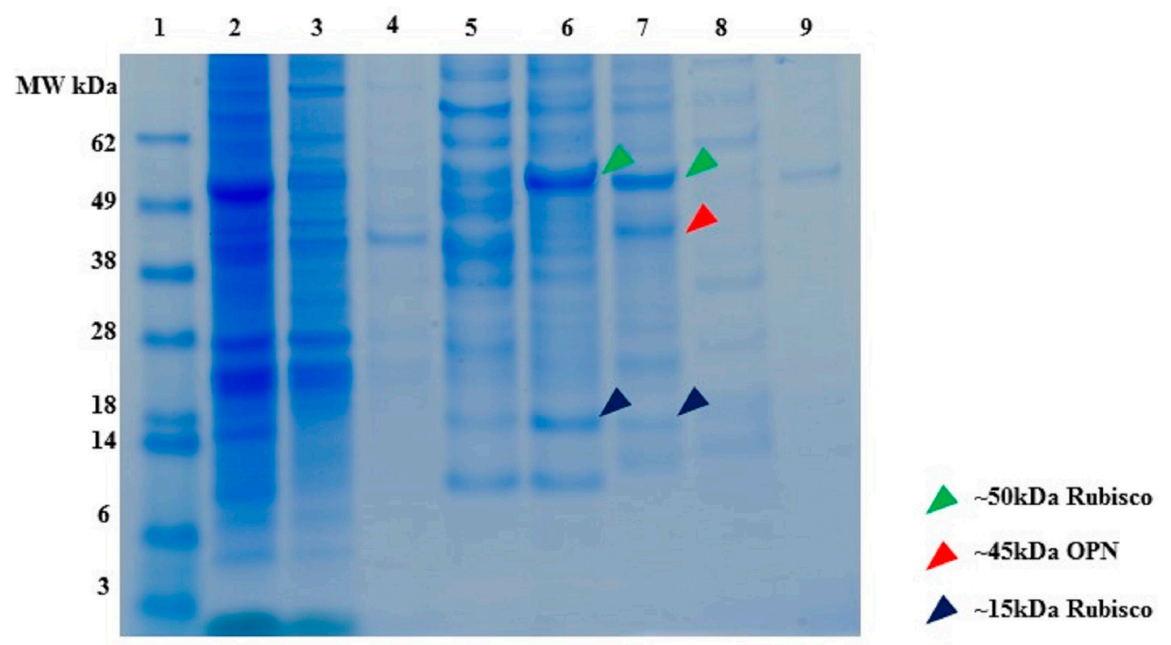

Figure 10. SDS-PAGE of $C$. reinhardtii lysate binding and elution profile from Capto $Q$ (strong anion exchange) resin. All samples diluted to $<1 \mathrm{mg} / \mathrm{mL}$ TSP. Lane 1. MW marker, lane 2. Clarified lysate, lane 3. Supernatant, lane 4. Washes (3 CV), lane 5. Elution with $100 \mathrm{mM} \mathrm{NaCl}$, lane 6. Elution with $200 \mathrm{mM} \mathrm{NaCl}$, lane 7. Elution with $300 \mathrm{mM} \mathrm{NaCl}$, lane 8. Elution with $500 \mathrm{mM} \mathrm{NaCl}$, lane 9. Elution with $1000 \mathrm{mM} \mathrm{NaCl}$. All elutions were performed with $5 \mathrm{CV}$ of the respective buffer.

\section{Materials and Methods}

\subsection{Cultivation of Recombinant Chlamydomonas reinhardtii Strain Expressing Bovine OPN}

The chloroplast genome of $C$. reinhardtii strain cc1670 was modified to express bovine OPN by California Center of Algae Biotechnology, UCSD [24]. The $p s b A$ gene was replaced with cDNA for bovine OPN (GenBank accession number NP_776612.1) by homologous recombination. The modified strain was rescued by re-insertion of the $p s b A$ gene at a different location in the genome. A $1 \times-F L A G$ epitope tag (DYKDDDDKS) was inserted at the $N$-terminal of OPN sequence for identification and quantification, with an enterokinase cleavage site to facilitate removal after OPN purification.

Recombinant algal cells were grown on 15\% Tris-Acetate-Phosphate (TAP) agar plates at room temperature. The colonies were transferred into TAP media containing $0.1 \%$ Hutner's trace solution (C. reinhardtii research center) and $150 \mu \mathrm{g} / \mathrm{mL}$ ampicillin $[39,40]$. The cells were grown in sterile 
conditions with constant $125 \mathrm{rpm}$ shaking, 200-300 $\mu \mathrm{mols} \mathrm{m}^{-2} \cdot \mathrm{s}^{-1}$ of cool white light at room temperature. They were harvested in mid-log phase at $\mathrm{OD}_{750}=0.5$ by centrifugation at $3500 \mathrm{rpm}$ and $4{ }^{\circ} \mathrm{C}$ (Allegra 25R, Beckman Coulter, Brea, CA, USA). The wet biomass was stored at $-80^{\circ} \mathrm{C}$.

\subsection{Recombinant E. coli Strain and Cultivation}

E. coli strain BL21 was modified to express bovine OPN with an $N$-terminal FLAG sequence for OPN identification and quantification similar to $C$. reinhardtii by California Center of Algae Biotechnology, UCSD. The recombinant strain was ampicillin resistant and OPN expression was controlled by the arabinose promotor.

$1 \mathrm{~mL}$ glycerol stock of the recombinant strain was used to grow overnight inoculum $(5 \mathrm{~mL})$ in Luria-Bertani (LB) media $\left(150 \mu \mathrm{g} / \mathrm{mL}\right.$ ampicillin) at $37^{\circ} \mathrm{C}$ and $200 \mathrm{rpm}$. The overnight inoculum was transferred to $1 \mathrm{~L}$ Terrific Broth (Sigma-Aldrich, St. Louis, MO, USA, Cat \# T0918) and E. coli cells were grown at $37{ }^{\circ} \mathrm{C}, 200 \mathrm{rpm}$ to $\mathrm{OD}_{600}=0.8$. OPN expression was induced overnight with $0.2 \%$ $(w / v)$ arabinose at $37^{\circ} \mathrm{C}$ and $200 \mathrm{rpm}$. The wet biomass was harvested by centrifugation and stored at $-80^{\circ} \mathrm{C}$.

\subsection{Batch Adsorption Chromatography and Purification Studies}

Frozen biomass was thawed to room temperature and suspended in $1 \mathrm{~g}$ biomass:10 $\mathrm{mL}$ lysis buffer (50 mM Tris, $150 \mathrm{mM} \mathrm{NaCl}, 1 \mathrm{mM}$ Ethylenediaminetetraacetic acid (EDTA), pH 7.4) containing protease and phosphatase inhibitor cocktail pills (Roche, Mannheim, Germany). Cells were lysed by sonication (15 min for C. reinhardtii and $5 \mathrm{~min}$ for E. coli) in $30 \mathrm{~s}$ on/off intervals at $4{ }^{\circ} \mathrm{C}$ using a sonicator (Sonifier 250 , Branson, Danbury, CT, USA) at $30 \%$ output control and $30 \%$ duty cycle with a micro probe $\left(1 / 8^{\prime \prime}\right.$ micro tip A3-561 Branson, Danbury, CT, USA). Cell lysates were centrifuged $(10,000 \times g$ for $20 \mathrm{~min}$ at $4{ }^{\circ} \mathrm{C}$, Allegra 25R centrifuge, Beckman Coulter, Brea, CA, USA) and cell-free supernatants were filtered through $0.22 \mu \mathrm{m}$ sterile polyethersulfone membrane syringe filter (30 $\mathrm{mm}$ diameter, Genesee Scientific, San Diego, CA, USA) and this was considered the clarified lysate for chromatography experiments. Protease and phosphatase inhibitor cocktail pills (Roche, Mannheim, Germany) in their recommended concentrations were added to all buffers used in the chromatography experiments.

FLAG-affinity chromatography. FLAG-affinity purification was used to obtain highly purified recombinant OPN for analysis. $1 \mathrm{~mL}$ of anti-FLAG affinity gel (Sigma-Aldrich, St. Louis, MO, USA, Cat \# A4596) was equilibrated in lysis buffer for $30 \mathrm{CV}$ and mixed with $5 \mathrm{~mL}$ of $C$. reinhardtii clarified lysate or $1 \mathrm{~mL}$ of $E$. coli clarified lysate. Incubation of resin and lysate was carried out for $2 \mathrm{~h}$ at $4{ }^{\circ} \mathrm{C}$ with continuous end-over-end mixing in a Glas-Col rotor (Glas-Col LLC, Terre Haute, IN, USA) at 33 rpm ( $40 \%$ speed control). The resin was separated from the clarified lysate by centrifuging at $6000 \times g$ for $5 \mathrm{~min}$ and the resin was loaded on a Bio Spin disposable chromatography column (Bio-Rad, Hercules, CA, USA, Cat \# 732-6008). Non-specifically bound proteins were removed by washing with $10 \mathrm{CV}$ of $50 \mathrm{mM}$ Tris, $150 \mathrm{mM} \mathrm{NaCl}, 1 \mathrm{mM}$ EDTA, $\mathrm{pH}$ 7.4. Proteins bound to resin were eluted using $5 \mathrm{CV}$ of $100 \mathrm{mM}$ Glycine, $400 \mathrm{mM} \mathrm{NaCl}, \mathrm{pH}$ 3.5. The $\mathrm{pH}$ of the eluted proteins was immediately raised to 8.0 by adding $50 \mu \mathrm{L}$ of $1 \mathrm{M}$ Tris- $\mathrm{HCl}$, to avoid protein denaturation at low $\mathrm{pH}$.

Ceramic hydroxyapatite chromatography. Clarified lysates were dialyzed against $5 \mathrm{mM}$ sodium phosphate (NaP) pH 6.8 for $2 \mathrm{~h}$ at $4{ }^{\circ} \mathrm{C}$ using snake-skin membrane ( $3.5 \mathrm{kDa}$ molecular weight cut-off, Thermo Fisher Scientific, Waltham, MA, USA, Cat \#68035). The clarified lysate (2.5 $\mathrm{mL}$ of $C$. reinhardtii clarified lysate, $0.66 \mathrm{~mL}$ of E. coli clarified lysate) was incubated for $1 \mathrm{~h}$ at room temperature by end-over-end mixing with $0.5 \mathrm{~mL}$ of ceramic hydroxyapatite resin (Bio-Rad, Hercules, CA, USA, Cat \# 1584000) pre-equilibrated in $5 \mathrm{mM} \mathrm{NaP} \mathrm{pH} 6.8$ and resin was loaded on a chromatography column. The resin was washed with $10 \mathrm{CV}$ of $5 \mathrm{mM} \mathrm{NaP} \mathrm{pH} 6.8$ followed by protein elution using a step-wise increasing concentration (100 mM, $250 \mathrm{mM}, 500 \mathrm{mM}, 1000 \mathrm{mM}$ and $1500 \mathrm{mM}$ ) of NaP buffers at pH 6.8 with $5 \mathrm{CV}$ of each buffer concentration.

Immobilized Metal Affinity Chromatography (IMAC). Gallium chloride at $400 \mathrm{mM}$ concentration was immobilized on Chelating Sepharose FF (GE Healthcare Life Sciences, Marlborough, MA, USA, 
Cat \# 17-0575-01) as per manufacturer instructions and equilibrated with $50 \mathrm{mM}$ MES, $500 \mathrm{mM} \mathrm{NaCl}$ $\mathrm{pH}$ 5.5. The C. reinhardtii and E. coli lysates were dialyzed against $50 \mathrm{mM}$ MES, $500 \mathrm{mM} \mathrm{NaCl} \mathrm{pH} 5.5$ for $2 \mathrm{~h}$ at $4{ }^{\circ} \mathrm{C}$ using snake-skin membrane ( $3.5 \mathrm{kDa}$ molecular weight cut-off). The dialyzed sample ( $2.5 \mathrm{~mL}$ of $C$. reinhardtii clarified lysate, $0.66 \mathrm{~mL}$ of $E$. coli clarified lysate) was incubated with $0.5 \mathrm{~mL}$ of Ga-IMAC resin for $1 \mathrm{~h}$ at room temperature and loaded on a chromatography column. The resin was washed with $10 \mathrm{CV}$ of $50 \mathrm{mM} \mathrm{MES}, 0.5 \mathrm{M} \mathrm{NaCl} \mathrm{pH} 5.5$, followed by protein elution using a step-wise increasing concentration (100 mM, $250 \mathrm{mM}, 500 \mathrm{mM}, 1000 \mathrm{mM}$ and $1500 \mathrm{mM})$ of NaP buffers with 5 $\mathrm{CV}$ of each buffer concentration.

Anion-exchange chromatography. The clarified lysates were dialyzed against $50 \mathrm{mM}$ Tris pH 7.0 for $2 \mathrm{~h}$ at $4{ }^{\circ} \mathrm{C}$ using snake-skin membrane (3.5 kDa molecular weight cut-off), to bring the conductivity to $4 \mathrm{mS}$. The dialyzed samples ( $2.5 \mathrm{~mL}$ of $C$. reinhardtii clarified lysate, $0.66 \mathrm{~mL}$ of E. coli clarified lysate) were incubated for $1 \mathrm{~h}$ at room temperature by end-over-end mixing with $0.5 \mathrm{~mL}$ of Capto $\mathrm{Q}$ resin (GE Healthcare Life Sciences, Marlborough, MA, USA, Cat \# 17-5316-10) equilibrated in $50 \mathrm{mM}$ Tris pH 7.0. The resin was separated by centrifuging at $6000 \times g$ for $5 \mathrm{~min}$ and loaded on a chromatography column. The resin was washed with $10 \mathrm{CV}$ of $50 \mathrm{mM}$ Tris $\mathrm{pH}$ 7.0, followed by protein elution using a step-wise increasing concentration $(100 \mathrm{mM}, 200 \mathrm{mM}, 300 \mathrm{mM}, 500 \mathrm{mM}, 1000 \mathrm{mM})$ of $\mathrm{NaCl}$ in $50 \mathrm{mM}$ Tris pH 7.0 with $5 \mathrm{CV}$ of each buffer concentration.

\subsection{Analytical Methods}

All total protein measurements were calculated using Bradford assay (Coomassie plus Assay kit, Thermo Fisher Scientific, Waltham, MA, USA, Cat \#23236) on a microtiter plate format with bovine serum albumin (BSA) as standard. The absorption was measured at $595 \mathrm{~nm}$ using VersaMax microplate reader (Molecular Devices, San Jose, CA, USA).

Proteins in sample were visualized and quantified using SDS-PAGE under reducing conditions. Denatured protein sample was loaded on NuPAGE Novex $4 \%-12 \%$ Bis-Tris pre-cast gradient gels (Thermo Fisher Scientific, Waltham, MA, USA, Cat \# NP0335BOX). The proteins were separated by electrophoresis for $35 \mathrm{~min}$ at constant $200 \mathrm{~V}$. All proteins were visualized by SimplyBlue SafeStain Coomassie G-250 stain (Thermo Fisher Scientific, Waltham, MA, USA, Cat \# LC6065). ImageJ software (v.1.49, U. S. National Institutes of Health, Bethesda, MD, USA) was used to calculate purity of proteins in each sample lane.

Anti-FLAG western blot were prepared by transferring protein bands from SDS-PAGE gels onto a nitrocellulose membrane using iBLOT transfer kit (Thermo Fisher Scientific, Waltham, MA, USA, Cat \# IB401002) for $7 \mathrm{~min}$. The membrane was blocked with $2.5 \%$ non-fat milk in $0.05 \%$ TBS-T for $1 \mathrm{~h}$ and washed $3 \times$ with $0.05 \%$ TBS-T. The blocked membrane was then incubated with anti-FLAG M2 alkaline phosphatase conjugated antibody solution (Sigma-Aldrich, St. Louis, MO, USA, Cat \# A9469) diluted 1:2000 in 0.05\% TBS-T for $1 \mathrm{~h}$ at room temperature on a gel rocker. The antibody solution was washed $3 \times$ with $0.05 \%$ TBS-T and developed for 2 min using a solution of NBT/BCIP developer pills (Sigma-Aldrich, St. Louis, MO, USA, Cat \# B5655) dissolved in $10 \mathrm{~mL}$ of distilled water. Standard curves with FLAG-affinity purified OPN were used to estimate OPN concentrations when necessary. ImageJ software (v.1.49, National Institutes of Health, Bethesda, Maryland, MD, USA) was used to calculate relative amounts (\%) of OPN in the fractions generated during adsorption chromatography experiments, normalized by the amount of OPN in the lysate. The $45 \mathrm{kDa}$ and fragments of OPN were all included in calculating the amount of OPN in each fraction. Rubisco subunits were confirmed using similar western blotting protocol. Anti-Rubisco large and small subunit polyclonal antibodies (Agrisera antibodies, Vännäs, Sweden) were used as primary antibodies (1:5000) and anti-rabbit-alkaline phosphatase (Sigma-Aldrich, St. Louis, MO, USA) as secondary antibody (1:5000).

Direct ELISA was used to determine OPN concentration in E. coli samples using FLAG-BAP (Sigma-Aldrich, St. Louis, MO, USA, Cat \# P7582) as standards. Samples were diluted in phosphate buffer saline (PBS) and incubated overnight at $4{ }^{\circ} \mathrm{C}$ on Nunc immunosorbent 96 -well plates. After 3 
washes with PBS-T, blocking solution of 0.3\% BSA in PBS was added to the 96-will plate and incubated for $2 \mathrm{~h}$ at $37^{\circ} \mathrm{C}$ followed by similar wash and incubation with anti-FLAG M2 antibody conjugated with horse radish peroxidase (Sigma-Aldrich, St. Louis, MO, USA, Cat \# A8592) diluted 1:5000 in PBS. TMB developer (Sigma-Aldrich, St. Louis, MO, USA, Cat \# T0440) was used to develop the reaction and stopped with $2 \mathrm{M} \mathrm{HCl}$, the absorbance was read at $450 \mathrm{~nm}$.

FLAG-affinity purified OPN samples at $50 \mu \mathrm{g} / \mathrm{mL}$ concentration were analyzed for their $\mathrm{pI}$ and molecular weight using 2D gel electrophoresis performed by Protein Chemistry Lab, Texas A\&M University, USA. $\mathrm{pI}$ resolution was performed with immobilized $\mathrm{pH}$ gradient technology (IPG Dry Strip, GE Healthcare Life Sciences, Marlborough, MA, USA) followed by electrophoresis on GE Healthcare Tall Mighty Small system $(8 \times 10 \mathrm{~cm})$. The resolved gel was silver stained to visualize OPN and specificity was confirmed by anti-FLAG western blot. The $\mathrm{pI}$ values of OPN were estimated using the standard curve established by the IPG Dry Strip manufacturer.

Phosphostaining was performed on FLAG-affinity purified OPN samples that were de-salted and de-lipidated by chloroform-methanol precipitation [41]. SDS-PAGE was performed as above and the gel was incubated in fixing solution (50\% methanol, $10 \%$ acetic acid and $40 \%$ MilliQ water) overnight at room temperature on the gel rocker. The gel was washed $3 \times$ with MilliQ water and stained with Pro-Q diamond phosphostain (Thermo Fisher Scientific, Waltham, MA, USA, Cat \# MPP33301) for 90 min in the dark. Destaining solution ( $20 \%$ acetonitrile in $50 \mathrm{mM}$ sodium acetate $\mathrm{pH} 4.0)$ was added $3 \times$ with $30 \mathrm{~min}$ incubation each and the gel was finally washed $4 \times$ with MilliQ water. Gel imaging was performed on Typhoon Trio fluorescent imaging system (GE Healthcare Life Sciences, Marlborough, MA, USA) at excitation $532 \mathrm{~nm}$ green and $560 \mathrm{~nm}$ bandpass emission filter.

\section{Conclusions}

Osteopontin was successfully expressed in the chloroplast of $C$. reinhardtii, a novel alternative platform for recombinant protein production, capable of performing phosphorylation as a post-translational modification. The $C$. reinhardtii strain expressed two major OPN isoforms (45 kDa and $35 \mathrm{kDa}$ ) with pI ranging from 3.5 to 4.5 due to heterogeneous post-translational phosphorylation.

Several chromatography resins were evaluated for isolating OPN by utilizing interactions with the phosphorylation and the unique polyaspartate sequence. Ceramic hydroxyapatite resin demonstrated affinity for acidic and phosphorylated proteins and adsorbed the phosphorylated OPN (45 kDa) isoform strongly. The adsorption and co-elution of phosphorylated host proteins like Rubisco along with $C$. reinhardtii OPN, reduced the purification efficiency of CHT resin. Since CHT could not distinguish between major phosphorylated impurities (Rubisco) and OPN, it is not ideal for separation of phosphorylated recombinant proteins from $C$. reinhardtii.

Gallium-IMAC, did not exhibit a preferential binding of phosphorylated OPN. Both phosphorylated OPN from C. reinhardtii and non-phosphorylated OPN from E. coli appeared to have similar binding and elution behavior with Ga-IMAC. Our study suggests that $\mathrm{Ga}^{3+}$ interacts with multiple carboxyl groups of OPN and host proteins and has no specific preference for the phosphorylated algal OPN $45 \mathrm{kDa}$ form. As such, Ga-IMAC resin does not offer any advantage over $\mathrm{CHT}$ as a potential purification method for phosphorylated OPN forms.

Anion exchange chromatography is a viable adsorption step for capturing OPN from both E. coli and C. reinhardtii clarified lysates. The anion exchange chromatography conducted under optimal adsorption, resin-wash and elution conditions removes as much as $50 \%$ of host protein while maintaining OPN recovery yield at $80 \%$. Other anionic protein impurities bound to the resin can be partially separated from OPN based on their strength of charge interactions with the amine ligand resulting in a $20 \%$ pure OPN fraction.

Because of low accumulation levels in our current $C$. reinhardtii strain leading to low starting concentration of OPN in the clarified C. reinhardtii lysate $(0.1 \%-0.2 \%$ TSP), the development of a scalable OPN purification train will probably require three or more chromatography steps. 
Supplementary Materials: Supplementary materials can be found at www.mdpi.com/xxx/s1.

Acknowledgments: This work was supported by NSF CBET-1160117 collaborative grant.

Author Contributions: Zivko L. Nikolov designed the study, methodology and co-wrote the manuscript. Ayswarya Ravi performed the C. reinhardtii experiments, data analysis and wrote the manuscript. Shengchun Guo carried out E. coli growth and batch purification experiments. Beth Rasala, Miller Tran and Stephen Mayfield provided the transgenic strains and advice on cultivation.

Conflicts of Interest: The authors declare no conflict of interest.

\section{Abbreviations}

$\begin{array}{ll}\text { CHO } & \text { Chinese hamster ovary } \\ \text { PTM } & \text { Post-translational modification } \\ \text { OPN } & \text { Osteopontin } \\ \text { BSP } & \text { Bone sialoprotein } \\ \text { NaP } & \text { Sodium phosphate } \\ \text { CHT } & \text { Ceramic hydroxyapatite } \\ \text { Ga-IMAC } & \text { Gallium-immobilized metal affinity chromatography } \\ \text { Rubisco } & \text { Ribulose-1, 5-bisphosphate carboxylase/oxygenase } \\ \text { TSP } & \text { Total soluble protein }\end{array}$

\section{References}

1. Baeshen, N.A.; Baeshen, M.N.; Sheikh, A.; Bora, R.S.; Ahmed, M.M.M.; Ramadan, H.A.I.; Saini, K.S.; Redwan, E.M. Cell factories for insulin production. Microb. Cell Fact. 2014, 13, 141. [CrossRef] [PubMed]

2. Rosano, G.L.; Ceccarelli, E.A. Recombinant protein expression in Escherichia coli: Advances and challenges. Front. Microbiol. 2014, 5, 172. [CrossRef] [PubMed]

3. Rasala, B.A.; Muto, M.; Lee, P.A.; Jager, M.; Cardoso, R.M.; Behnke, C.A.; Kirk, P.; Hokanson, C.A.; Crea, R.; Mendez, M. Production of therapeutic proteins in algae, analysis of expression of seven human proteins in the chloroplast of Chlamydomonas reinhardtii. Plant Biotechnol. J. 2010, 8, 719-733. [CrossRef] [PubMed]

4. Gong, Y.; Hu, H.; Gao, Y.; Xu, X.; Gao, H. Microalgae as platforms for production of recombinant proteins and valuable compounds: Progress and prospects. J. Ind. Microbiol. Biotechnol. 2011, 38, 1879-1890. [CrossRef] [PubMed]

5. Specht, E.; Miyake-Stoner, S.; Mayfield, S. Micro-algae come of age as a platform for recombinant protein production. Biotechnol. Lett. 2010, 32, 1373-1383. [CrossRef] [PubMed]

6. Munjal, N.; Garzon-Sanabria, A.J.; Quinones, K.W.; Gregory, J.; Nikolov, Z.L. Light-induced production of an antibody fragment and malaria vaccine antigen from Chlamydomonas reinhardtii. Processes 2014, 2, 625-638. [CrossRef]

7. Sierra, L.S.; Dixon, C.K.; Wilken, L.R. Enzymatic cell disruption of the microalgae Chlamydomonas reinhardtii for lipid and protein extraction. Algal Res. 2017, 25, 149-159. [CrossRef]

8. Mazzali, M.; Kipari, T.; Ophascharoensuk, V.; Wesson, J.; Johnson, R.; Hughes, J. Osteopontin-A molecule for all seasons. QJM 2002, 95, 3-13. [CrossRef] [PubMed]

9. Xanthou, G.; Alissafi, T.; Semitekolou, M.; Simoes, D.C.; Economidou, E.; Gaga, M.; Lambrecht, B.N.; Lloyd, C.M.; Panoutsakopoulou, V. Osteopontin has a crucial role in allergic airway disease through regulation of dendritic cell subsets. Nat. Med. 2007, 13, 570-578. [CrossRef] [PubMed]

10. Sodek, J.; Ganss, B.; McKee, M.D. Osteopontin. Crit. Rev. Oral Biol. Med. 2000, 11, 279-303. [CrossRef] [PubMed]

11. Kazanecki, C.C.; Uzwiak, D.J.; Denhardt, D.T. Control of osteopontin signaling and function by post-translational phosphorylation and protein folding. J. Cell. Biochem. 2007, 102, 912-924. [CrossRef] [PubMed]

12. Sørensen, E.S.; Petersen, T.E.; Højrup, P. Posttranslational modifications of bovine osteopontin: Identification of twenty-eight phosphorylation and three O-glycosylation sites. Protein Sci. 1995, 4, 2040-2049. [CrossRef] [PubMed] 
13. Gericke, A.; Qin, C.; Spevak, L.; Fujimoto, Y.; Butler, W.; Sørensen, E.; Boskey, A. Importance of phosphorylation for osteopontin regulation of biomineralization. Calcif. Tissue Int. 2005, 77, 45-54. [CrossRef] [PubMed]

14. Weber, G.F.; Zawaideh, S.; Hikita, S.; Kumar, V.A.; Cantor, H.; Ashkar, S. Phosphorylation-dependent interaction of osteopontin with its receptors regulates macrophage migration and activation. J. Leukoc. Biol. 2002, 72, 752-761. [PubMed]

15. Jono, S.; Peinado, C.; Giachelli, C.M. Phosphorylation of osteopontin is required for inhibition of vascular smooth muscle cell calcification. J. Biol. Chem. 2000, 275, 20197-20203. [CrossRef] [PubMed]

16. Stubbs, J.T. Generation and use of recombinant human bone sialoprotein and osteopontin for hydroxyapatite studies. Connect. Tissue Res. 1996, 35, 393-399. [CrossRef] [PubMed]

17. Xuan, J.W.; Hota, C.; Chambers, A.F. Recombinant GST-human osteopontin fusion protein is functional in RGD-dependent cell adhesion. J. Cell. Biochem. 1994, 54, 247-255. [CrossRef] [PubMed]

18. Jang, J.-H.; Kim, J.-H. Improved cellular response of osteoblast cells using recombinant human osteopontin protein produced by escherichia coli. Biotechnol. Lett. 2005, 27, 1767-1770. [CrossRef] [PubMed]

19. Ashkar, S.; Teplow, D.; Glimcher, M.; Saavedra, R. In vitro phosphorylation of mouse osteopontin expressed in E. coli. Biochem. Biophys. Res. Commun. 1993, 191, 126-133. [CrossRef] [PubMed]

20. Senger, D.R.; Perruzzi, C.A.; Papadopoulos, A.; Tenen, D.G. Purification of a human milk protein closely similar to tumor-secreted phosphoproteins and osteopontin. Biochim. Biophys. Acta (BBA) Protein Struct. Mol. Enzymol. 1989, 996, 43-48. [CrossRef]

21. Sørensen, S.; Justesen, S.J.; Johnsen, A.H. Purification and characterization of osteopontin from human milk. Protein Expr. Purif. 2003, 30, 238-245. [CrossRef]

22. Bayless, K.J.; Davis, G.E.; Meininger, G.A. Isolation and biological properties of osteopontin from bovine milk. Protein Expr. Purif. 1997, 9, 309-314. [CrossRef] [PubMed]

23. Azuma, N.; Maeta, A.; Fukuchi, K.; Kanno, C. A rapid method for purifying osteopontin from bovine milk and interaction between osteopontin and other milk proteins. Int. Dairy J. 2006, 16, 370-378. [CrossRef]

24. Mayfield, S.P.; Hallgren, A.C.; Rasala, B.A.; Tran, M.; Mayfield, M. Colostrum/Milk Protein Compositions. U.S. Patents US2015/016460, 27 August 2015.

25. Gao, Y.A.; Agnihotri, R.; Vary, C.P.; Liaw, L. Expression and characterization of recombinant osteopontin peptides representing matrix metalloproteinase proteolytic fragments. Matrix Biol. 2004, 23, 457-466. [CrossRef] [PubMed]

26. Denhardt, D.T.; Guo, X. Osteopontin: A protein with diverse functions. FASEB J. 1993, 7, 1475-1482. [CrossRef] [PubMed]

27. Terpe, K. Overview of bacterial expression systems for heterologous protein production: From molecular and biochemical fundamentals to commercial systems. Appl. Microbiol. Biotechnol. 2006, 72, 211-222. [CrossRef] [PubMed]

28. Ferrer-Miralles, N.; Domingo-Espín, J.; Corchero, J.L.; Vázquez, E.; Villaverde, A. Microbial factories for recombinant pharmaceuticals. Microb. Cell Fact. 2009, 8, 17. [CrossRef] [PubMed]

29. Fakruddin, M.; Mohammad Mazumdar, R.; Bin Mannan, K.S.; Chowdhury, A.; Hossain, M.N. Critical factors affecting the success of cloning, expression and mass production of enzymes by recombinant $E$. coli. ISRN Biotechnol. 2013, 2013, 7. [CrossRef] [PubMed]

30. Gagnon, P.; Latiff, S.M.A.; Cai, C.; Lau, W.; Lim, C.L. IgM purification with hydroxyapatite. Available online: http:/ /www.bioprocessintl.com/upstream-processing/biochemicals-raw-materials/igmpurification-with-hydroxyapatite-349783/ (accessed on 8 February 2018).

31. Gagnon, P. Monoclonal antibody purification with hydroxyapatite. New Biotechnol. 2009, 25, $287-293$. [CrossRef] [PubMed]

32. Losh, J.L.; Young, J.N.; Morel, F.M.M. Rubisco is a small fraction of total protein in marine phytoplankton. New Phytol. 2013, 198, 52-58. [CrossRef] [PubMed]

33. Aryal, U.K.; Olson, D.J.H.; Ross, A.R.S. Optimization of immobilized gallium (iii) ion affinity chromatography for selective binding and recovery of phosphopeptides from protein digests. J. Biomol. Tech. 2008, 19, $296-310$. [PubMed]

34. Machida, M.; Kosako, H.; Shirakabe, K.; Kobayashi, M.; Ushiyama, M.; Inagawa, J.; Hirano, J.; Nakano, T.; Bando, Y.; Nishida, E.; et al. Purification of phosphoproteins by immobilized metal affinity chromatography and its application to phosphoproteome analysis. FEBS J. 2007, 274, 1576-1587. [CrossRef] [PubMed] 
35. Zhu, Y.S.; FitzGerald, R.J. Caseinophosphopeptide enrichment and identification. Int. J. Food Sci. Technol. 2012, 47, 2235-2242. [CrossRef]

36. Biswas, S.; Sarkar, A.; Misra, R. Iron affinity gel and gallium immobilized metal affinity chromatographic technique for phosphopeptide enrichment: A comparative study. Biotechnol. Biotechnol. Equip. 2017, 31, 639-646. [CrossRef]

37. Yuan, Y.; Zhang, X.; Weng, S.; Guan, W.; Xiang, D.; Gao, J.; Li, J.; Han, W.; Yu, Y. Expression and purification of bioactive high-purity recombinant mouse spp1 in escherichia coli. Appl. Biochem. Biotechnol. 2014, 173, 421-432. [CrossRef] [PubMed]

38. Weng, S.Y.; Zhou, L.; Guan, W.; Deng, Q.; Chen, H.H.; Han, W.; Yu, Y.; Yuan, Y.S. High-purity recombinant osteopontin n-terminal domain. Acta Biochim. Biophys. Sin. 2015, 47, 758-760. [CrossRef] [PubMed]

39. Hutner, S.; Provasoli, L.; Schatz, A.; Haskins, C. Some approaches to the study of the role of metals in the metabolism of microorganisms. Proc. Am. Philos. Soc. 1950, 94, 152-170.

40. Gorman, D.S.; Levine, R. Cytochrome $\mathrm{f}$ and plastocyanin: Their sequence in the photosynthetic electron transport chain of chlamydomonas reinhardi. Proc. Natl. Acad. Sci. 1965, 54, 1665-1669. [CrossRef] [PubMed]

41. Wessel, D.; Flügge, U.I. A method for the quantitative recovery of protein in dilute solution in the presence of detergents and lipids. Anal. Biochem. 1984, 138, 141-143. [CrossRef]

(c) 2018 by the authors. Licensee MDPI, Basel, Switzerland. This article is an open access article distributed under the terms and conditions of the Creative Commons Attribution (CC BY) license (http://creativecommons.org/licenses/by/4.0/). 